\title{
Hearing Loss in Migraine: An Uncommon Manifestation of a Common Disorder
}

\author{
Nikita Dhar ${ }^{1}$ Ritu Shree ${ }^{1}$ Divya M. Radhakrishnan ${ }^{1}$ \\ ${ }^{1}$ Department of Neurology, All India Institute of Medical Sciences, \\ Rishikesh, Uttarakhand, India
}

J Neurosci Rural Pract:2020;11:508-508

Migraine is the most common cause of headache-related disability, females being more commonly affected. ${ }^{1}$ Bright light, loud noise, or any particular odor or food are potential markers of the premonitory phase of migraine. ${ }^{1}$ While migrainous headache in some cases may be preceded by transient sensory or visual symptoms, few other cases may have associated tinnitus, vertigo, and nystagmus. ${ }^{1,2}$ We report a case of migraine with sudden onset sensorineural hearing loss (SNHL) responding to antimigrainous therapy along with oral corticosteroids.

A 26-year-old medical trainee with past history of migrainous headache presented with 1-day history of severe rightsided throbbing headache along with right ear hearing loss. She also complained of nausea, photophobia, and phonophobia. Neurological examination was unremarkable except for right ear SNHL. Pure tone audiometry showed right-sided high frequency SNHL of $30 \mathrm{db}$ at 4 and $8 \mathrm{~Hz}$ with normal left ear hearing sensitivity. Magnetic resonance imaging brain failed to reveal any significant abnormality. She was started on naproxen $500 \mathrm{mg}$ p.o. BID for 5 days along with a 2-week tapering course of oral prednisolone with an initial dose of $1 \mathrm{mg} / \mathrm{kg} / \mathrm{day}$. Her headache and hearing loss improved over 3 to 5 days, and pure tone audiometry repeated 2 weeks later documented complete improvement with normal hearing sensitivity in both ears.

Although pathophysiology of migraine is still unclear, various genetic, environmental, metabolic, and hormonal factors have been implicated. They may result in hypothalamic and brainstem activation along with reorganization of the brain circuitry, primarily the thalamo-cortical circuits, and release of neuropeptides including calcitonin gene-related peptide and pituitary adenylate cyclase-activating polypeptide. ${ }^{3}$ Common auditory manifestations in migraine including phonophobia, tinnitus, variable hearing impairment, and vertigo may result from either vasospasm of small arterioles in cochlea or labyrinth or vasospasm of internal auditory artery or migrainous infarction. ${ }^{4}$ It appears likely that spasm of cochlear vessels led

\author{
Niraj Kumar ${ }^{1}$
}

Address for correspondence Niraj Kumar, MD, DM, Department of Neurology, All India Institute of Medical Sciences, Rishikesh, Uttarakhand, India 249203 (e-mail: drnirajkumarsingh@gmail.com).

to a reversible hypoxic injury and temporary hearing loss in our patient. Use of steroids in sudden SNHL lacks a clear consensus but is widely being used. ${ }^{5}$ Although we cannot rule out a spontaneous recovery of SNHL in our case, steroids might have also contributed.

Development of migrainous headache along with sudden onset right-sided SNHL without tinnitus, which recovered with therapy for migraine and oral prednisolone favored the likelihood of SNHL resulting from vasospasm of cochlear vessels. Thus, hearing loss may be an unusual manifestation in migraine.

\section{Authors' Contributions}

N. D. contributed in conception, design, and writing the first manuscript. D. M. R. and R. S. supported in review and critique. N. K. dedicated in conception, design, review, and critique.

\section{Funding \\ None.}

\section{Conflict of Interest}

None declared.

\section{References}

1 Charles A. Migraine. N Engl J Med 2017;377(6):553-561

2 Headache classification committee of the International Headache Society (IHS). The International Classification of Headache Disorders. 3rd ed. Cephalalgia; 2018:1-211. Available at: https://ichd-3.org/wp-content/uploads/2018/01/ The-International-Classification-of-Headache-Disorders3rd-Edition-2018.pdf Accessed May 5, 2020

3 Charles A. The pathophysiology of migraine: implications for clinical management. Lancet Neurol 2018;17(2):174-182

4 Viirre ES, Baloh RW. Migraine as a cause of sudden hearing loss. Headache 1996;36(1):24-28

5 Conlin AE, Parnes LS. Treatment of sudden sensorineural hearing loss: I. A systematic review. Arch Otolaryngol Head Neck Surg 2007;133(6):573-581 